\title{
Diclofenac toxicity in Gyps vulture is associated with decreased uric acid excretion and not renal portal vasoconstriction
}

\author{
V. Naidoo ${ }^{a}$ and G.E. Swan ${ }^{a}$
}

${ }^{\mathrm{a}}$ Section of Pharmacology, Faculty of Veterinary Science, Onderstepoort, South Africa

\begin{abstract}
Diclofenac (DF), a non-steroidal anti-inflammatory drug (NSAID), is largely regarded as one of the most devastating environmental toxicant in recent times, after accidental exposure via their food-chain lead to massive mortalities in three vulture species on the Asian subcontinent. Although the use of diclofenac was recently banned on the Indian subcontinent, following the favourable safety profile of meloxicam, its mechanism of toxicity remains unknown. In an attempt to establish this mechanism, we test three hypotheses using models established from either the domestic chicken (Gallus domesticus) or the African Whitebacked vulture (Gyps africanus). We demonstrate that both DF and meloxicam are toxic to renal tubular epithelial (RTE) cells following $12 \mathrm{~h}$ of exposure, due to an increase in production of reactive oxygen species (ROS), which could be temporarily ameliorated by preincubation with uric acid (UA). When cultures were incubated with either drug for only $2 \mathrm{~h}$, meloxicam showed no toxicity in contrast to diclofenac. In both cases no increase in ROS production was evident. In addition, diclofenac decreased the transport of uric acid, by interfering with the p-amino-hippuric acid (PAH) channel. We conclude that vulture susceptibility to diclofenac results from a combination of an increased ROS, interference with UA transport and the duration of exposure.
\end{abstract}

Keywords: Diclofenac; Vulture; Mechanism of toxicity; Vulture crisis

\section{Introduction}

Three species of vultures endemic to South Asia are in grave danger of extinction across the Asian subcontinent. Populations of Oriental White-backed vulture (Gyps bengalensis), Longbilled vulture (G. indicus) and Slender-billed vulture (G. tenuirostris) have declined by more than $97 \%$ in India, Pakistan and Nepal, with the result that all three species have been 
classified by the IUCN, the World Conservation Union, as being critically endangered (Satheesan, 1999, Satheesan, 2000, Prakash, 1999, Prakash et al., 2003 and Pain et al., 2003). Although the devastation was first noticed in the early 1990s, it was not until 2004 that Oaks et al. linked the vulture deaths to the veterinary use of diclofenac (DF), a non-steroidal antiinflammatory drug (NSAID)(Shultz et al., 2004 and Oaks et al., 2004). This causal relationship was subsequently confirmed under controlled experimental conditions in both captive Asian and African white-backed vultures (G. africanus)(Oaks et al., 2004 and Swan et al., 2006b). More recently the Egyptian vulture (Neophron percnopterus) and red-headed vulture (Sarcogyps calvus) have also been shown to be declining (Cuthbert et al., 2006). Although the vulture population decline has been conclusively linked to the veterinary use of DF, the drug mechanism for the species crash has yet to be explained. The latter is mainly confounded by the relatively safe use of diclofenac in the medical industries for a number of years (Roberts and Morrow, 2001). More importantly the reason why the $\mathrm{LD}_{50}$ of 0.098 to $0.225 \mathrm{mg} / \mathrm{kg}$ reported in vulture is substantially lower that reported in rodents is also unknown (Swan et al., 2006b). However, with the necropsies undertaken showing the common finding of diffuse visceral gout and proximal convoluted tubular damage, it has been concluded that kidneys or its supportive vascular system are the site of toxicity (Meteyer et al., 2005, Oaks et al., 2004 and Swan et al., 2006b). The latter is not completely unexpected as diclofenac is known to be a nephrotoxic agent at higher doses in people (Hickey et al., 2001).

Meteyer et al. (2005) proposed the inhibition of renal prostaglandins (PG) and subsequent closure of the renal portal valves as causes of severe renal ischemia and nephrotoxicity. In this theory, toxicity was related to the unique avian blood supply, in which a large proportion of the blood supply to the renal proximal convoluted tubules arises from the hind-quarters via the renal portal system (Burrows et al., 1983). More importantly within these blood vessels, structures known as renal portal valves regulate renal perfusion by shunting blood directly to the caudal vena cava under conditions characterised by stress. Meteyer et al. (2005) suggested that a decrease in the formation of the vasodialatory prostaglandins (PG), via DF's cyclo-oxygenase inhibitory activity, could promote valve closure thereby shunting blood away from the kidney and thereby promote renal ischemia. Although the influence of the drug on PG is well described in literature, it has also been shown that the valve needs to open to shunt blood away from the kidney (Burrows et al., 1983). Furthermore with valve control being mediated by the beta adrenergic and muscarinic receptors (Burrows et al., 1983), and not the prostaglandins, Meteyer hypothesis appears to be inaccurate. The theory does, 
however, have merit in that renal vascular tone is maintained by PG making it plausible that DF could influence the PGs mediating venodialation thereby induce ischemia (Dunn and Hood, 1977).

For the second theory advanced, $\mathrm{Ng}$ et al. (2006) used rodent kidney epithelial to demonstrate that DF could be nephrotoxic due to oxidative damage to renal tubular cell (RTE) mitochondria with subsequent activation of the apoptotic cycle. In a second study, $\mathrm{Ng}$ et al. (2008) were also able to demonstrate that both DF and meloxicam (MLX) could induce cellular apoptosis, with MLX being the less toxic molecule. Although the theory explained the clinical signs evident, the study failed to consider possible differences between mammalian and avian physiology.

In addition, we propose that toxicity may be related to drug's ability to influence UA excretion as studies by Naidoo et al. (2007) demonstrated that the main clinical signs of depression, following exposure to diclofenac, was a direct result of the marked increase in plasma uric acid concentrations. Since the mammalian kidney is influenced by the uricosuric effects of DF and MLX through the inhibition of the epithelial cell's basolateral UA-excreting organic anionic transporters (OATs) (also referred to as a PAH transporter), multi-drug resistance protein (MRP) and the apical UA reabsorptive channel known as URAT1, it is possible that a similar effect occurs in the vulture. The latter is plausible as similar PAH and MRP channels are involved with UA excretion in the chicken (birds do not reabsorbed UA) (Khamdang et al., 2002, Rafey et al., 2003, Dudas et al., 2005, Enomoto and Endou, 2005 and Mount et al., 2006). In addition both diclofenac and phenylbutazone have been shown to induce uricemia in the chicken (Berger et al., 1960 and Naidoo et al., 2007).

To test the above hypotheses, toxicity assays were undertaken using tissue harvested from the domestic chicken, a previously validated model. The majority of assays used MLX as a control as this NSAID was previously established safe in Gyps vultures (Swan et al., 2006a).

\section{Material and methods}

\subsection{Chemical and consumables}

Diclofenac, Meloxicam, Penicillin, Streptomycin, Dichlorofluorescin diacetate (DCFH-DA), Di-methyl sulphoxide (DMSO), 3-(4,5-dimethylthiazolyl-2)-2,5-diphenyltetrazolium bromide (MTT), trypsin, norepinephrine (NE), $\mathrm{NaCl}, \mathrm{KCl}, \mathrm{MgSO}_{4}, \mathrm{NaHCO}_{3}, \mathrm{KH}_{2} \mathrm{PO}_{4}, \mathrm{CaCl}_{2}$, EDTA, glutamine, sodium 1-lactate, sodium pyruvate, Glucose and HEPES, p-amino-hippuric acid (PAH) were obtained from Sigma South Africa. Debulco's modified Eagles's essential 
medium with l-glutamine (DMEM), foetal calf serum (FCS), Hanks balanced salt solution (HBSS), phosphate buffered saline (PBS) was obtained from Highveld biologicals South Africa. The 96 and 24 well plates and anopore membrane culture inserts were obtained from NUNC, South Africa.

\subsection{Animals}

The Broiler chickens ( $G$. domesticus) $(n=10)$ used in the study were raised at the Poultry Reference Laboratory (Onderstepoort, South Africa) on a commercial broiler diet and water ad lib. The chickens were euthanized at 5 weeks of age by cervical dislocation. One African sub-adult White-back vulture (G. africanus) of unknown age that required euthanasia due to a severe injury was also used. The vulture had not previously been treated with any analgesic and received only fluid therapy intraperitoneally. Euthanasia was performed using pentobarbitone intravenous.

\subsection{Dose extrapolations}

For the organ bath studies, the concentration of diclofenac and meloxicam tested represent the maximum plasma concentration of these drugs in vultures. For the toxicity and transporter assay, the concentrations tested are based on the extrapolated $\mathrm{LD}_{50}$ of the diclofenac/meloxicam in the chicken and vulture, depending on which cells were used (Naidoo et al., 2007 and Naidoo et al., 2008a).

\subsection{Organ bath studies}

The cranial renal portal vein was dissected away from the parenchyma of the chicken kidney. The vein was suspended in physiological saline solution (PSS) containing calcium and contractile studies undertaken as previously described (Hessellund et al., 2003). The dissected vessels were attached onto the force transducer of a myograph (Danish Myo Technology) and allowed to equilibrate for $60 \mathrm{~min}$ in oxygenated $\mathrm{PSS}\left(5 \% \mathrm{CO}_{2}\right.$ in air). Initial contraction was stimulated with potassium chloride and thereafter with NE $(10 \mu \mathrm{mol})$. Once the basal NE contractile level was established, DF $(0.42 \mu \mathrm{mol})$ or MLX $(0.66 \mu \mathrm{mol})$ were evaluated in combination with NE $(10 \mu \mathrm{mol})$. The effect of the drugs on each tissue was repeated three times at the same dose. Prior to the addition of each treatment, the wells were thoroughly flushed at least three times, allowing the tissue to equilibrate prior to re-stimulation with $\mathrm{NE}+$ drugs. NE was selected as the agonist as NE has been shown to have contractile response in the kidneys of birds (Jungbluth et al., 1994). In addition studies in the equivalent amphibian structure indicate the renal portal veins are predominantly NE responsive (Judith 
and Gibbins, 1983). DF was tested in quadruplicate and MLX in duplicate due to a failure in the tissue to contract despite being harvested and maintained under the same conditions.

\subsection{In vitro $\mathrm{RTE}$ assay}

All assays were repeated in triplicate in a plate and were repeated on three different occasions.

\subsubsection{Establishing of cell cultures}

From the chickens and the vulture, the kidneys were harvested immediately after euthanasia, minced with a scalpel blade and incubated overnight in DMEM with $1 \mathrm{mg} / \mathrm{ml}$ of collagenase at $37^{\circ} \mathrm{C}$ (Freshney, 1987). The following morning cell homogenates were passed through a 250 and $38 \mu \mathrm{m}$ filter to isolate the RTE cells (Trifillis, 1999). The isolated cells were washed three times by centrifugation at $200 \times \mathrm{g}$ with PBS and re-suspended in DMEM supplemented with 10\% FCS, streptomycin and penicillin G (Trifillis, 1999).

\subsubsection{Toxicity assay}

Chicken RTE cells, $200 \mu \mathrm{l}\left(10^{5}\right.$ cells $\left./ \mathrm{ml}\right)$ were seeded into 96-well plates ( $\mathrm{Lu}$ et al., 2004). The assays were allowed to establish over $48 \mathrm{~h}$, prior to incubation with drug. Following the predetermined intervals of 12, 24 and $48 \mathrm{~h}$, the cultures were incubated with MTT (0.44 umol) for $5 \mathrm{~h}$ (Lu et al., 2004, Orfila et al., 2000 and Gerlier and Thomasset, 1986). The degree of formazan formation was determined by rinsing the wells with HBSS prior to the addition of $50 \mu \mathrm{l}$ of DMSO and subsequent reading on a Varion spectrophotometer at $570 \mathrm{~nm}$ (1 $\mathrm{cm}$ path length). Cell survival was evaluated as a percentage of viable cells of treated to untreated wells on the same plate (\% Cell Viability).

To ascertain if the drug toxicity was related to the duration of exposure, and therefore the pharmacokinetic profile of DF or MLX, chicken RTE cells were incubated with either DF or MLX for only $2 \mathrm{~h}$ ( 2 half-lives in the chicken), flushed with HBSS three times and replaced with fresh medium. Toxicity was evaluated as for the standard toxicity assay.

\subsubsection{ROS studies}

Chicken RTE cells were grown as for the toxicity assay. The cells were incubated with DF or MLX in the presence or absence of the uric acid for 6,8 and $12 \mathrm{~h}$. The cell cultures were thereafter incubated with DCFH-DA, a specific indicator of intracellular ROS formation, for 30 min and washed with HBSS (Gomez-Lechon et al., 2003). The change in absorption was read at on a Varion spectrophotometer at $504 \mathrm{~nm}$ (Somogyi et al., 2007). The delayed toxic effect was determined using the same culture method as for the toxicity assay. The degree of 
ROS production was evaluated as a percentage of the ROS production of treated to untreated wells on the same plate.

\subsection{Influence on uric acid clearance}

To ascertain if either DF or MLX had an influence on UA transport in vivo, stored serum samples following the intravenous DF $(n=4)$ at $0.8 \mathrm{mg} / \mathrm{kg}$ and intramuscular MLX administration $(n=4)$ at $2 \mathrm{mg} / \mathrm{kg}$ from $G$. corprotheres were analysed for the change in serum UA concentration in the first $2 \mathrm{~h}$ following dosing (Naidoo et al., 2008a). Uric acid was measured with an $\mathrm{ACE} \mathrm{EM}^{\mathrm{TM}}$ Uric Acid reagent kit by the rate of $\alpha$-oxoglutarate conversion to 1-malate (Nexet Chemistry Analyser, Alfa Wasserman, Bayer SA).

To determine the in vitro influence on UA transport, chicken or vulture RTE cells, $500 \mu 1$ $\left(10^{6}\right.$ cells $\left./ \mathrm{ml}\right)$ were seeded onto the anopore membrane culture inserts, in 24 well microplates and fed every three days (Ichida et al., 2003). After seven days of incubation, the culture medium was replaced with the HBSS transport medium as previously described (Ichida et al., 2003, Sutterlan and Laverty, 1998 and Waugh, 2006). The reaction was started by adding the drug into the basal well. Cell integrity was initially established by the addition of inulin into each well. For the standard assay the chicken RTE assays were exposed to various concentrations of DF $(n=4)$ and $\operatorname{MLX}(n=2)$ following $2 \mathrm{~h}$ of incubation to ascertain their effect on PAH excretion. PAH was used as it is a specific transport substrate for the OAT transporter. PAH concentrations were analysed as previously described (Agarwal, 2002). The change in concentration in each well was established as the difference from the start to the stop of incubation. The net transport was calculated as the change in the basolateral concentration subtracted from the apical change.

The assay was subsequently repeated with the limited available vulture RTE cells with UA (Analysed as above). Net excretion was determined as for PAH. The bird in question was an African White-backed vulture (G. africanus). The kidney tissue was harvested as described above.

\subsection{Statistics and repeatability}

DF in organ baths was repeatable on four occasions. All toxicity assays were assessed in triplicate for each point on three different occasions, while the PAH transporter studies assessed in duplicate on two separate occasions. Vulture assays could not be repeated due to the absence of sufficient organs for harvesting. Results are presented as mean \pm the standard error of the mean (SEM). Significance per drug concentration in comparison to the control 
was assessed using ANOVA and the post-hoc Dunnett's $t$-test. For organ baths, PAH transport and in vivo change in UA excretion difference over time were compared to pre-drug concentration using the paired $t$-test (SPSS 13, SPSS Inc.).

\section{Results}

\subsection{Organ bath studies}

When the venous tissue was pre-incubated with either $\operatorname{MLX}(n=2)$ or DF $(n=4)$, the contractile response of the tissues were significantly lower $(p=0.028$ for DF) than the response to NE in the absence of NSAID (Control) i.e. they promoted vasodilatation (Fig. 1). Additionally the reduced contractile responsive was non-reversible despite complete flushing of the wells over a period of time.

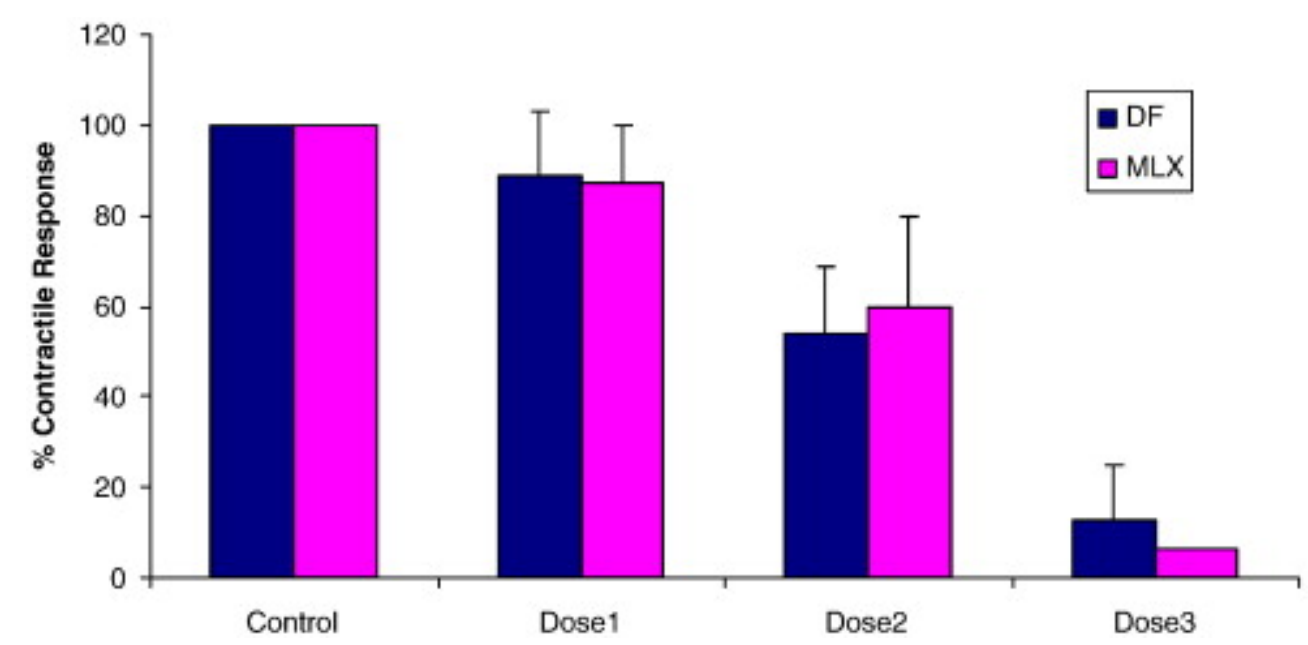

Fig. 1. Contractile response of cranial renal portal veins to norepinephrine (NE) alone (control) or the response to NE following co-incubated with either diclofenac (DF) or meloxicam (MLX) as a single dose of drug. Dose 1 to Dose 3 illustrates the additive inhibitory effect of the NSAIDs in an irreversible manner, as the chambers were thoroughly flushed prior to each dose. Results are presented as mean \pm SEM.

\subsection{In vitro cell toxicity studies}

The chicken RTE cells were susceptible to the toxic effects of DF and MLX in a concentration ( $n=9 /$ dose/drug) and time ( $n=9 /$ dose/drug) responsive manner (Fig. 2$)$, with the first signs of toxicity being evident as early as $12 \mathrm{~h}$ post-incubation. In all cases toxicity 
was associated with an increased production of ROS from $6 \mathrm{~h}$ post-incubation to peak by as much as $200 \%$ by $12 \mathrm{~h}$ post-incubation (Fig. 2).
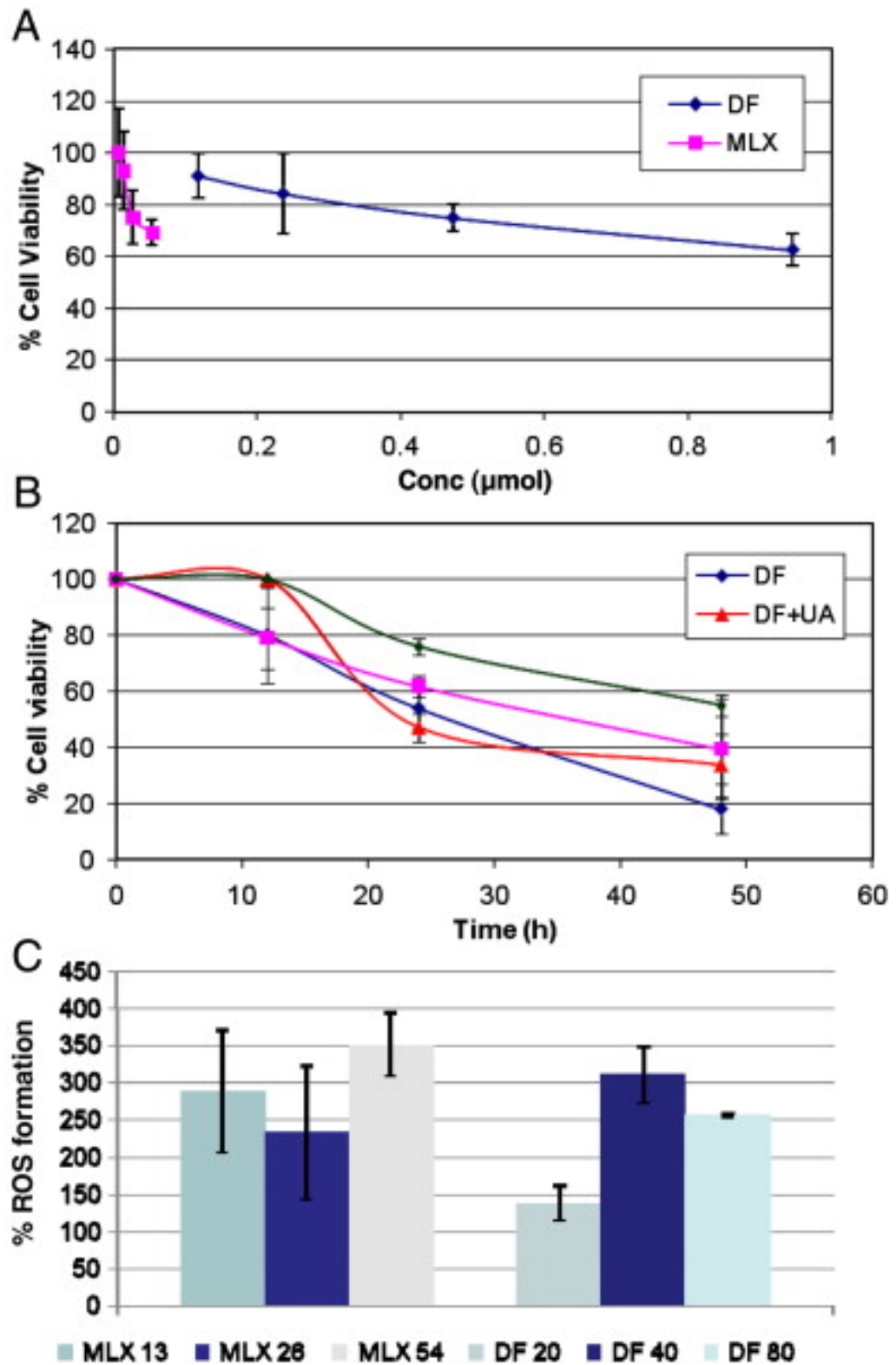

Fig. 2. Direct cell toxicity of DF and MLX following variable periods of incubation and/or concentrations using the MTT assay. Results are presented as mean \pm SEM. A) chicken RTE cell viability following 12 h of incubation with DF or MLX at four concentrations; B) chicken RTE cell viability following incubation with DF (470 nmol) or MLX (13 nmol) in the absence and presence of UA over $48 h+U A$-indicates that the cultures were incubated concurrently with UA for the assay; C) ROS production measured within RTE cells using DCFH-DA after $12 \mathrm{~h}$ of incubation. Results are presented as a percentage of the control \pm SEM. 
For the cultures incubated with uric acid, the first signs of toxicity were only evident at $24 \mathrm{~h}$ post-incubation. The ROS production was not quantifiable in these chambers as UA is known to interfere with the DCFH-DA reagent.

\subsection{Uric acid clearance}

The two groups of birds had different UA concentrations at zero hours. This difference was not significant $(p=0.4)$ and also within the normal range established for the White-backed vulture (Naidoo et al., 2008b). While both MLX and DF appeared to induce an increase in plasma UA ( $n=4 /$ drug) (Fig. 3), only the DF effect was significantly differently from the pre-dosing sample with the $2 \mathrm{~h}$ time point being the most significant $(p=0.037)$.

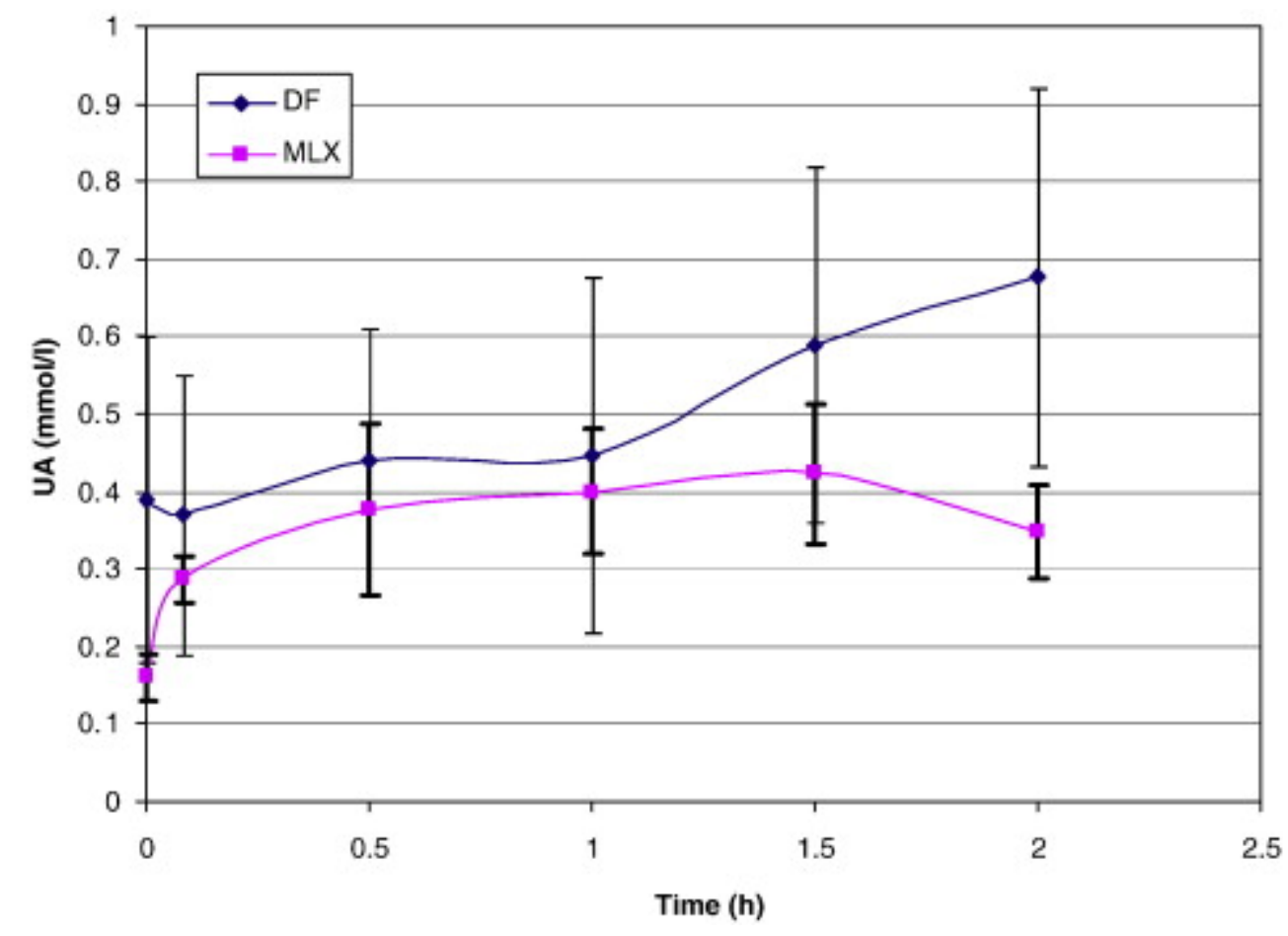

Fig. 3. In vivo change in serum UA concentration for G. corprotheres over the first $2 \mathrm{~h}$ following the administration of MLX $(n=4)$ or DF $(n=4)$. Results are presented as mean $\pm \mathrm{SEM}$.

All three concentrations of DF $(n=4)$ significantly decreased net PAH transport, $(p=0.021)$ in a non-dose responsive manner (Fig. 4). Although meloxicam did appear to influence PAH clearance, the effect was not significant $(p=0.3)$. To rule out interspecies differences, the assay was repeated with the limited available vulture RTE cells using UA. All three 
concentrations of DF $(n=2)$ tested, promoted a concentration dependent decrease in UA clearance. In contrast MLX ( $n=2)$ had a weak non-significant biphasic effect (Fig. 4).

A

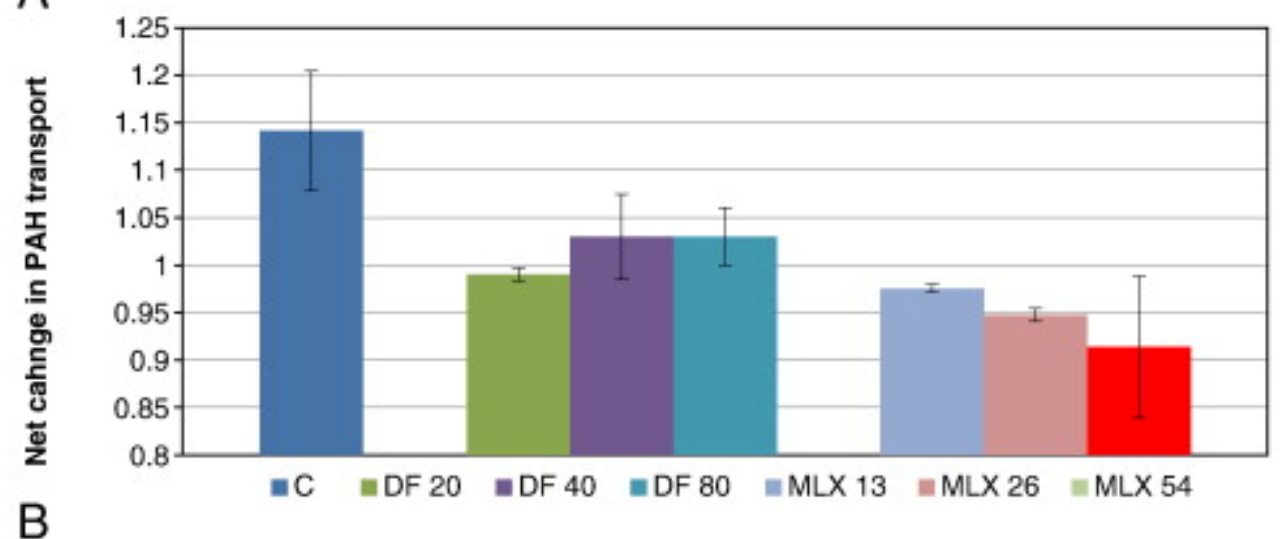

B

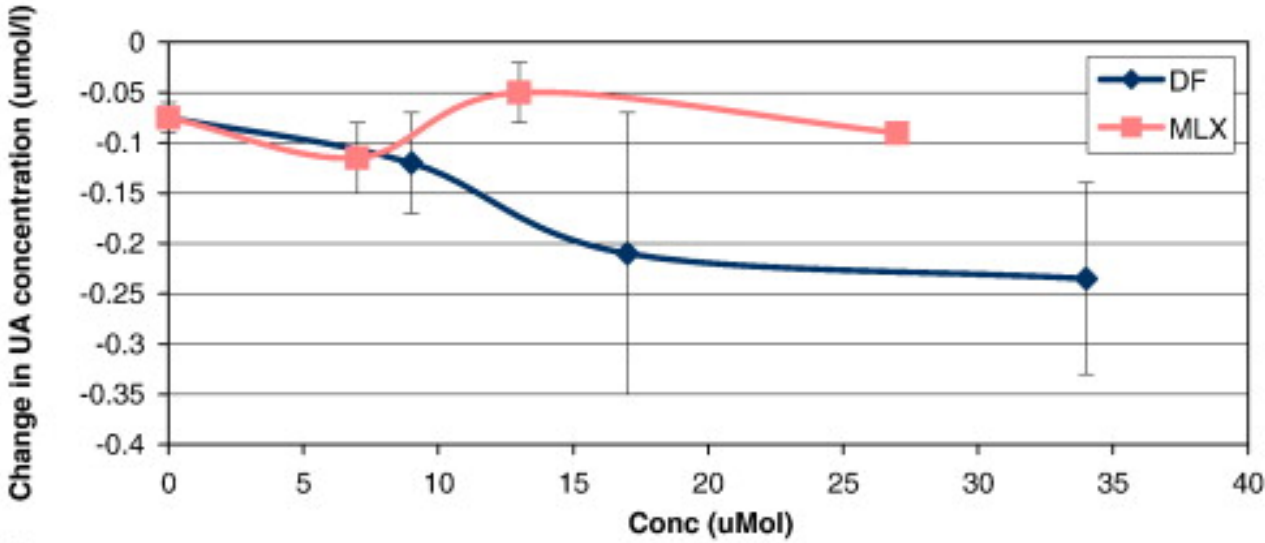

C

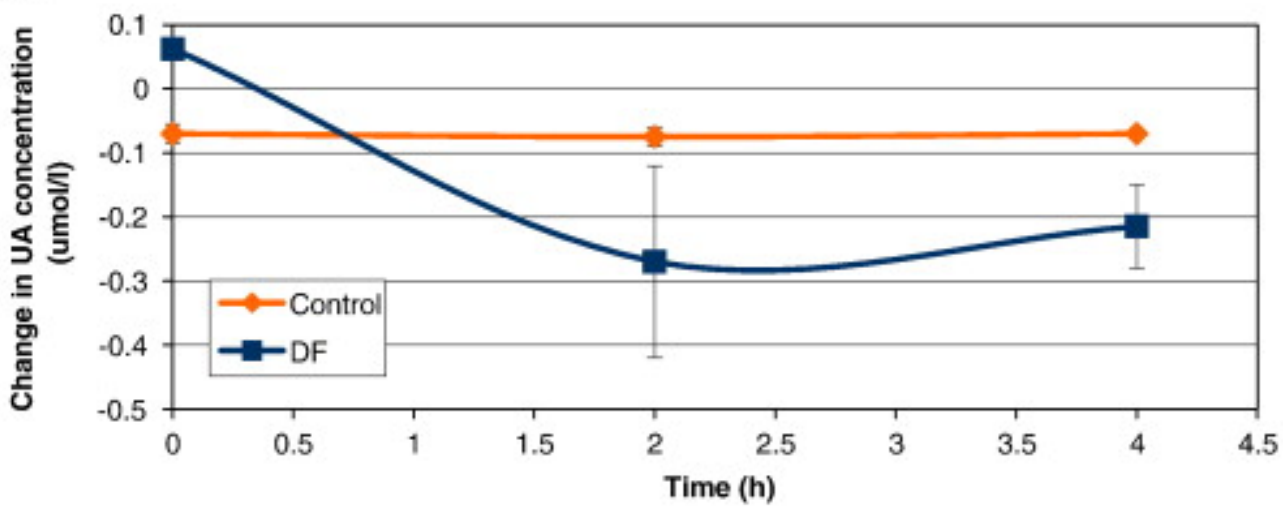

Fig. 4. Influence of DF or MLX on UA or PAH clearance in cell cultures established in double chambered well. Results are presented as mean \pm SEM. A) change in PAH concentration for chicken RTE cells following $2 \mathrm{~h}$ of incubation with DF and MLX;B) change in UA concentrations for vulture RTE cells following incubation with DF and MLX for $2 \mathrm{~h}$; C) Change in UA concentration for vulture RTE cells, 2 and $4 \mathrm{~h}$ following the removal of DF from chamber. 


\section{Discussion}

From the organ bath studies it is evident that neither DF nor MLX had the potential to enhance vascular contractility in the bird tissue. This finding was not considered unusual as a similar effect was evident when rat portal veins were exposed to diclofenac (Shimamura et al., 2005). Although the finding is contradictory to glomerular arterial physiology in mammals, it can be explained by finding of Peredo (2003) who demonstrated that indomethacin decreased mesenteric vasoconstriction by inhibiting contractile $\mathrm{PG} \mathrm{f}_{2} \alpha$ production via cyclo-oxygenase (COX) inhibition (Peredo, 2003). With both diclofenac and meloxicam being COX inhibitors it will explain the similar effect to indomethacin.

For the in vitro toxicity cell death was evaluated by the inability of the cell culture to reduce the dye MTT. With the mitochondria being the only organelle capable of reducing MTT, to formazan, the resultant cell death could only be due to the death of the cellular mitochondria. This is in support of the findings of (Ng et al., 2006) and (Ng et al., 2008) especially with the toxicity being associated with a $200 \%$ increase in ROS production. For both diclofenac and meloxicam, the avian primary cells were much more susceptible than the mammalian cultures as reported by $\mathrm{Ng}$ et al. (2008) (> 100 fold, based on the concentration reported to kill $40 \%$ of the cell culture), and was in line with the lower median lethal dose $\left(\mathrm{LD}_{50}\right)$ reported for the chicken (Naidoo et al., 2007). Unlike Ng et al. (2008), MLX was toxic to the avian cells at much lower concentrations than DF. However, since the concentrations tested where based on the true plasma concentrations from the chicken, and with both drugs inducing the same degree of cell death in vitro, we conclude that MLX and DF can both be toxic to the kidneys RTE cell to the same extent.

While mitochondrial toxicity with subsequent ROS formation is a plausible mechanism, the cultures in the above assay were continuously exposed to DF and MLX for $12 \mathrm{~h}$, which failed to consider the short half-life of $0.6 \mathrm{~h}$ of DF in the chicken i.e. chicken toxicity was not related to long-term exposure. In the case of MLX no vulture was exposed to plasma concentrations above $5 \mu \mathrm{g} / \mathrm{ml}$ for more than $0.5 \mathrm{~h}$ (Naidoo et al., 2007 and Naidoo et al., 2008a). When cultures were exposed to DF and MLX for only $2 \mathrm{~h}$, no toxicity was evident for both MLX while DF remained significantly toxic ( $p<0.05$ for all concentrations) thereby indicating an alternate or additional mechanism behind toxicity.

To ascertain if this alternate mechanism was related to the depletion of intracellular UA, as proposed, cultures were incubated concurrently with UA. In all cases cell survival was promoted for $24 \mathrm{~h}$, corresponding to the first in vivo signs of toxicity in poisoned birds (Fig. 
2) (Swan et al., 2006b). With UA being an important intracellular anti-oxidant and the culture grown in the absence of UA showing an increase in ROS, the prolonged cell survival appears to be due to the buffering offered by the exogenous UA (Bekker, 1993). The short duration of protection was, however, unexpected tending to suggest that the UA absorption/secretion by the cell was being influenced. When the latter was studied further using the artificial renal tubules, it was evident that DF decreased the transport of UA by interfering with the PAH transporter in both chicken and vulture cells (The latter was very limited as the samples were being difficult to obtain as the species is endangered.)

The in vitro effect of DF was similar to the in vivo effects as DF stimulated an increase in plasma uric acid for the entire $2 \mathrm{~h}$ period. Interestingly this increase was related to the drug's half-life i.e. DF which has a long half-life $\left(T_{1 / 2}= \pm 12 \mathrm{~h}\right)$ had a prolonged influence on plasma uric acid concentrations while the opposite was true for meloxicam $\left(T_{1 / 2}= \pm 0.5 \mathrm{~h}\right)$. While the increase in vulture plasma UA concentrations could be explained by constant inhibition of the channels brought about by constant drug exposure, the drug was completely excreted from the chicken $8 \mathrm{~h}$ post-exposure, despite signs of toxicity seen $48 \mathrm{~h}$ later, indicating the possibility of irreversible channel inhibition. To ascertain if DF could inhibit transporters after drug withdrawal, the vulture RTE cells were exposed to DF for $5 \mathrm{~h}$ followed by complete flushing of the chambers $(n=2)$, prior to commencing the transporter assay. Similar to previously results, DF induced an increase in UA concentrations in both the apical and basolateral wells (Net decrease in UA excretion). More importantly the total concentration of UA in each well was greater than that added (Fig. 4), indicating that DF depleted the cell of UA.

With chickens RTE cells being susceptible to the toxic effect of DF and MLX as the result of the inhibition of the OAT/PAH transporters, it may therefore be concluded that diclofenac interferes with uric acid transport at the level of the kidney, thereby depriving the cell on an important anti-oxidant. Although this does explain the ability of the drug to induce toxicity in both the chicken and vulture, it fails to explain the greater sensitivity of the vultures. The sensitivity may, however, be explained by the pharmacokinetics half-life of 2 and $14 \mathrm{~h}$ in the chicken and vulture, respectively and the results from the ROS study, in which exposure to diclofenac for only periods above $12 \mathrm{~h}$ enhanced ROS production. Therefore while general toxicity results from the loss of an intracellular anti-oxidant, the additional production of ROS from the long-term exposure to diclofenac enhances the overall oxidative stress experience by the RTE cells i.e. they lose an anti-oxidant while being exposed to greater ROS production. The importance of the drug's half-life in toxicity is highlighted as meloxicam, a 
drug know to be safe in vultures, only becomes toxic in vitro toxicity when exposure times is extended beyond the drugs in vivo mean residence time.

\section{Acknowledgements}

This project was approved by the Animal Use and Care committee of the University of Pretoria. Vulture research was approved by Gauteng Nature Conservation and undertaken with the aid of the Lion and Rhino Conservation non-profit organisation. This project was funded by the Royal Society for the Protection of Birds (RSPB), the National Research Foundation of South Africa (NRF) and Bayer Animal Health South Africa.

\section{References}

Agarwal, 2002 R. Agarwal, Rapid microplate method for PAH estimation, Am. J. Physiol. Renal Physiol. 283 (2002), pp. 236-241.

Bekker, 1993 B.F. Bekker, Towards the physiological function of uric acid, Free Radic. Biol. Med. 14 (1993), pp. 615-631.

Berger et al., 1960 L. Berger, Y.T. Fan and A.B. Gutman, Effect of drugs that alter uric acid excretion in man on uric acid clearance in the chicken, Am. J. Physiol. 198 (1960), pp. 575580.

Burrows et al., 1983 M.E. Burrows, E.J. Braun and S.P. Duckles, Avian renal portal valve: a re-examination of its innervation, Am. J. Physiol. 245 (1983), pp. H628-H634.

Cuthbert et al., 2006 R. Cuthbert, D.R. Green, S. Ranada, S. Saravanan, D. Pain, V. Prakash and A.A. Cunningham, Rapid population declines of Egyptian Vulture (Neophron Percnopterus) and Red-Headed Vulture (Sarcogyps Calvus) in India, Anim. Conserv. 9 (2006), pp. 349-354.

Dudas et al., 2005 P.L. Dudas, R.M. Pelis, E.J. Braun and J.L. Renfro, Transepithelial urate transport by avian renal proximal tubule epithelium in primary culture, J. Exp. Biol. 22 (2005), pp. 4305-4315. 
Dunn and Hood, 1977 M.J. Dunn and V.L. Hood, Prostaglandins and the kidney, Am. J. Physiol. 233 (1977), pp. F169-F184.

Enomoto and Endou, 2005 A. Enomoto and H. Endou, Roles of organic anion transporters (OATs) and a urate transporter (URAT1) in the pathophysiology of human disease, Clin. Exp. Nephrol. 9 (2005), pp. 195-205.

Freshney, 1987 R.I. Freshney, Culture of Animal Cells, Wiley-Liss, New York (1987).

Gerlier and Thomasset, 1986 D. Gerlier and N. Thomasset, Use of MTT colorimetric assay to measure cell activation, J. Immunol. Methods 94 (1986), pp. 57-63.

Gomez-Lechon et al., 2003 M.J. Gomez-Lechon, X. Ponsoda, E. O'Connor, T. Donato, J.V. Castell and R. Jover, Diclofenac induces apoptosis in hepatocytes by alteration of mitochondrial function and generation of ROS, Biochem. Pharmacol. 66 (2003), pp. 21552167.

Hessellund et al., 2003 A. Hessellund, P. Jeppesen, C. Aalkjaer and T. Bek, Characterisation of vasomotion in porcine retinal arterioles, Acta Ophthalmol. Scand. 81 (2003), pp. 278-282.

Hickey et al., 2001 E.J. Hickey, R.R. Raje, V.E. Reid, S.M. Gross and S.D. Ray, Diclofenac induced in vivo nephrotoxicity may involve oxidative stress-mediated massive genomic DNA fragmentation and apoptotic cell death, Free Radic. Biol. Med. 31 (2001), pp. 139-152.

Ichida et al., 2003 K. Ichida, M. Hosoyamada, H. Kimura, M. Takeda, Y. Utsunomiya, T. Hosoya and H. Endou, Urate transport via human PAH transporter HOAT1 and its gene structure, Kidney Int. 63 (2003), pp. 143-155.

Jungbluth et al., 1994 D. Jungbluth, C. Simon-Oppermann, H. Schütz, R. Gerstberger and E. Simon, Noradrenergic modulation of avian kidney function, Comp. Biochem. Physiol. A 108 (1994), pp. 7-17.

Judith and Gibbins, 1983 L.M. Judith and I.L. Gibbins, Innervation of the renal vasculature of the toad (Bufo marinus), Cell Tissue Res. 231 (1983), pp. 357-376. 
Khamdang et al., 2002 S. Khamdang, M. Takeda, R. Noshiro, S. Narikawa, A. Enomoto, N. Anzai, P. Piyachaturawat and H. Endou, Interaction of human organic anion transporters and human organic cationic transporters with nonsteroidal anti-inflammatory drugs, $J$. Pharmacol. Exp. Ther. 303 (2002), pp. 534-539.

Lu et al., 2004 Y. Lu, A. Kawashima, I. Horii and L. Zhong, Effects of BSO and 1-cysteine on drug-induced cytotoxicity in primary cell cultures: drug-, cell type, and species-specific differences, Drug Chem. Toxicol. 27 (2004), pp. 269-280.

Meteyer et al., 2005 C.U. Meteyer, B.A. Rideout, M. Gilbert, H.L. Shivaprasad and J.L. Oaks, Pathology and proposed pathophysiology of diclofenac poisoning in free-living and experimentally exposed Oriental White-Backed Vultures (Gyps Bengalensis), J. Wildl. Dis. 41 (2005), pp. 707-716.

Mount et al., 2006 D.B. Mount, C.Y. Kwon and K. Zandi-Nejad, Renal urate transport, Rheum. Dis. Clin. North Am. 32 (2006), pp. 313-331.

Naidoo et al., 2007 V. Naidoo, N. Duncan, L. Bekker and G. Swan, Validating the domestic fowl as a model to investigate the pathophysiology of diclofenac in gyps vultures, Environ. Toxicol. Pharmacol. 24 (2007), pp. 260-266.

Naidoo et al., 2008a V. Naidoo, K. Wolter, D. Cromarty, P. Bartels, L. Bekker, L. McGaw, M. Taggart, R. Cuthbert and G. Swan, The pharmacokinetics of meloxicam in gyps vultures, J. Vet. Pharmacol. Ther. 31 (2008), pp. 128-134.

Naidoo et al., 2008b V. Naidoo, K. Wolter, M. Dietman and G.E. Swan, Establishment of selected baseline blood chemistry and hematological parameters in captive and wild-caught African White-backed vulture (Gyps africanus), J Wildl. Dis. 44 (2008), pp. 649-654.

$\mathrm{Ng}$ et al., 2006 L.E. Ng, A.S. Vincent, B. Halliwell and K.P. Wong, Action of diclofenac on kidney mitochondrial function, Biochem. Biophys. Res. Commun. 348 (2006), pp. 494-500.

Ng et al., 2008 L.E. Ng, B. Halliwell and K.P. Wong, Nephrotoxic cell death by diclofenac and meloxicam, Biochem. Biophys. Res. Commun. 369 (2008), pp. 873-877. 
Oaks et al., 2004 J.L. Oaks, M. Gilbert, M.Z. Virani, R.T. Watson, C.U. Meteyer, B.A. Rideout, H.L. Shivaprasad, S. Ahmed, M.J. Chaudhry, M. Arshad, S. Marmood, A. Ali and A.A. Khan, Diclofenac residues as the cause of vulture population decline in Pakistan, Nature 427 (2004), pp. 630-633.

Orfila et al., 2000 L. Orfila, M. Rodrýguez, T. Colman, M. Hasegawa and F. Arvelo, Structural modification of berberine alkaloids in relation to cytotoxic activity in vitro, $J$. Ethnopharmacol. 71 (2000), pp. 449-456.

Pain et al., 2003 D.J. Pain, A.A. Cunningham, P.F. Donald, J.W. Duckworth, D.C. Houston, J.T. Katzner, J. Parry-jones, C. Poole, V. Prakash, P. Round and R. Timmins, Causes and effects of temporospatial declines of gyps vultures in Asia, Conserv. biol. 17 (2003), pp. 661671.

Peredo, 2003 H.A. Peredo, Opposite effects of endogenous nitric oxide and prostaglandin F2 $\alpha$ in the rat mesenteric bed, Auton. Autacoid Pharmacol. 23 (2003), pp. 167-172.

Prakash, 1999 V. Prakash, Status of vultures in Keoladeo National Park, Bharatpur, Rajasthan, With special reference to population crash in gyps species, J. Bombay Nat. Hist. Soc. 96 (1999), pp. 365-378.

Prakash et al., 2003 V. Prakash, D.J. Pain, A.A. Cunningham, P.F. Donald, N. Prakash, A. Verma, R. Gargi, S. Sivakumar and A.R. Rahmani, Catastrophic collapse of Indian WhiteBacked Gyps Begalensis and Long-Billed Gyps Indicus vulture populations, Biol. Conserv. 109 (2003), pp. 381-390.

Rafey et al., 2003 M.A. Rafey, M.S. Lipkowitz, E. Leal-Pinto and R.G. Abramson, Uric acid transport, Curr. Opin. Nephrol. Hypertens. 12 (2003), pp. 511-516.

Roberts and Morrow, 2001 L.J. Roberts and J.D. Morrow, Analgesics-antipyretics and antiinflammatory agents and drugs employed in the treatment of gout (Chapter 10). In: J.L. Hardman, L.E. Limbird and A.G. Gilman, Editors, Goodman and Gilman's The Pharmacological Basis of Therapeutics 10'th ed., McGaw Hill Publisher, USA (2001), pp. $722-725$. 
Satheesan, 1999 S.M. Satheesan, The decline of vultures in India, Vulture News 40 (1999), pp. 35-36.

Satheesan, 2000 S.M. Satheesan, The role of poisons in the Indian vulture crash, Vulture News 42 (2000), p. 4.

Shimamura et al., 2005 K. Shimamura, S. Kimura, M. Zhou, Y. Wang, M. Toba, A. Ohashi, T. Higuchi, H. Kawaguchi and K. Kitamura, Evidence for the involvement of the cyclooxygenase-metabolic pathway in diclofenac-induced inhibition of spontaneous contraction of rat portal vein smooth muscles, J. Smooth Muscle Res. 41 (2005), pp. 195-206.

Shultz et al., 2004 S. Shultz, H.S. Baral, C. Sheonaidh, A.A. Cunningham, D. Devojit, G.R. Ghalsasi, M.S. Goudar, R.E. Green, A. Jones, N. Prashant, D.J. Pain and P. Vibhu, Diclofenac poisoning is widespread in declining vulture populations across the Indian subcontinent, Proc. R. Soc. Lond. B Biol. Sci. 271 (2004), pp. S458-S460.

Somogyi et al., 2007 A. Somogyi, K. Rosta, P. Pusztai, Z. Tulassay and G. Nagy, Antioxidant measurement, Physiol. Meas. 28 (2007), pp. R41-R55.

Sutterlan and Laverty, 1998 G.G. Sutterlan and G. Laverty, Characterisation of a primary cell culture model of the avian renal proximal tubule, Am. J. Physiol. 275 (1998), pp. R220R226.

Swan et al., 2006a G. Swan, V. Naidoo, R. Cuthbert, R.E. Green, D.J. Pain, S. Devendra, P. Vibhu, M. Taggart, L. Bekker, D. Devojit, J. Diekmann, M. Diekmann, E. Killian, A. Meharg, R.C. Patra, S. Mohini and K. Wolter, Removing the threat of diclofenac to critically endangered Asian vultures, PLoS Biol. 4 (2006), p. e66.

Swan et al., 2006b G.E. Swan, R. Cuthbert, M. Quevedo, R.E. Green, D.J. Pain, P. Bartels, A.A. Cunningham, N. Duncan, A. Meharg, J.L. Oaks, J. Parry-Jones, S. Schultz, M.A. Taggart, G.H. Verdoorn and K. Wolter, Toxicity of diclofenac in gyps vultures, Biol. Lett. 2 (2006), pp. 1-4. 
Trifillis, 1999 A.L. Trifillis, Isolation, culture and characterization of human renal proximal tubule and collecting duct cells, Exp. Nephrol. 7 (1999), pp. 353-359.

Waugh, 2006 W.H. Waugh, Photometry of inulin and polyfructosan by use of a cysteine/tryptophan reaction, Clin. Chem. 23 (2006), pp. 639-645. 